\title{
Experimental games for developing institutional capacity to manage common water infrastructure in India
}

\author{
Thomas Falk $^{\mathrm{a}, *}$, Shalander Kumar ${ }^{\mathrm{a}}$, Srinivasa Srigiri ${ }^{\mathrm{a}, \mathrm{b}}$ \\ ${ }^{a}$ Research Program on Innovation Systems for the Drylands, International Crops Research Institutefor the Semi-Arid Tropics, Patancheru, 502 324, Telangana, India \\ ${ }^{\mathrm{b}}$ Social Outlook Consulting, Plot 636 and 629, Matrusri Nagar, Miyapur, Hyderabad 500 049, Telangana, India
}

\section{A R T I C L E I N F O}

\section{Keywords:}

Watershed management

Capacity development

Games for sustainability

Social learning

Facilitation tools

India

\begin{abstract}
A B S T R A C T
Since the 1990s, India invested more than one billion USD in participatory watershed development. Amongst other interventions, the rehabilitation of small-scale water harvesting infrastructure is a main focus. Nevertheless, despite its multiple economic and ecological benefits, many communities fail to maintain the structures. External support in this regard focuses largely on the promotion of blueprint solutions such as community water funds or organizational capacity development of Water User Associations. Little attention is paid to supporting the communities in developing rules related to the actual water and water infrastructure management.

In this study we explored how experimental games closely framed to local conditions can help to better understand coordination challenges and develop institutional capacities related to managing small village reservoirs in Rajasthan/India. We played artefactual public good experiments with 300 water managers and combined the games with discussions. The approach created awareness for the cooperation challenges, facilitated debate related to possible solutions and helped to better understand cooperation patterns.

Our results suggest that participants were playing substantially better than the predictions of standard economic theory but also substantially better than the behavior observed in real life. The discussions showed that the players connected the game to their real life experiences. They highlighted challenges but also gave examples where cooperation in the community is working well. The games allowed them to experiment in a compressed way with different institutions which deepened the discussion.
\end{abstract}

\section{Introduction}

Many irrigation systems, especially in developing countries, exhibit characteristics of common pool resources (CPRs) and are managed as common property. Often, a group jointly maintains infrastructure, whereby the investment of each individual generates positive externalities for the whole group. Standard economic theory predicts that this leads to free riding behavior, and consequently, under-investment in resource provision (Olson, 2009).

In Rajasthan, India, water has traditionally been stored on the surface in minor irrigation dams and farm ponds which also recharge shallow groundwater aquifers. There is strong evidence that such structures have the potential to achieve a wide range of societal goals, such as enhancing the provision of ecosystem services, increasing productivity and generating diverse income opportunities (Raju and Shah, 2000; Kerr, 2002; Rockström et al., 2010; Garg et al., 2011, 2012; Singh et al., 2014; Karlberg et al., 2015; Kumar et al., 2016). Nevertheless, despite its obvious potential, many communities fail to maintain the structures and to sustain the provision of ecosystem services over time (Joshi et al., 2005; Bouma, 2008).

One reason is that minor irrigation dams are often common pool resources, where there are incentives to freeride on the (e.g. maintenance) investments of others (Bouma, 2008; Balooni et al., 2008). Wherever local institutions are weak, this will lead to a breakdown in community efforts to sustainably manage the infrastructure. Farmers report that traditional institutions, norms and rules have often been able to successfully address this challenge. Since the colonial times, however, state interference has weakened customary rules, leading to the gradual decline in the importance of minor irrigation dams since the 19th century (Reyes-Garcia et al., 2011; Raju and Shah, 2000; Palanisami and Meinzen-Dick, 2001).

Globally, new community-based water management schemes are being developed in response to similar institutional challenges (Gleick, 1998; Marshall, 2008; Campbell and Vainio-Mattila, 2003; Falk et al.,

\footnotetext{
* Corresponding author.

E-mail address: t.falk@cgiar.org (T. Falk).
} 
2009; Cox et al., 2010). In India, watershed development programs targeting communities are being implemented by government and nongovernment development actors. Water User Associations were and are created under the Rajasthan Farmers' Participation in Management of Irrigation Systems Act No. 21 of 2000. They are supposed to be local authorities that manage water and water infrastructure with local maintenance funds. The associations are equipped with use and management rights (Government of Rajasthan (GoR, 2000; Raju and Shah, 2000). In many cases, the systems work well as long as there is strong external facilitation (Raju and Shah, 2000). In most cases, infrastructure maintenance collapses as soon as the projects come to an end. There is evidence that standard mechanisms of establishing watershed maintenance funds often negatively affect the individual's willingness to contribute to maintenance (Bouma, 2008). Motivated by our awareness of these challenges, we used a framed Public-Good Experiment to answer our first research question:

Research question 1. What are the current behavioral patterns among Rajasthan water managers with regard to the management of water harvesting infrastructure?

While the lack of understanding is one aspect of our sustainability challenges, equally important is the need to develop adaptive capacities to respond to social-ecological system dynamics (Pahl-Wostl et al., 2008). The main aim of this study is to support improved management of water harvesting infrastructure. Understanding people's behavioral patterns and underlying norms was our starting point to challenge them to change behavior (Rajabu, 2007; Flood et al., 2018). More specifically, we studied the potential of using behavioral experiments to facilitate social learning and innovation. This requires institutional innovation which can be supported by collaborative learning (Woodhill, 2010). Experimental games are known to have the potential to support stakeholders in collaborative learning (Barreteau et al., 2001, 2003; Gurung et al., 2006; Guyot and Honiden, 2006; Becu et al., 2008; Meinzen-Dick et al., 2016; Flood et al., 2018). They can facilitate dialogue, shared learning, collective decision making and strengthen the adaptive management capacity of local communities (Gurung et al., 2006; Hertzog et al., 2014; Falk et al., 2016). The game setting allows experimenting with rules and strategies. It limits the cost of trial and error methods and shifts the approach from costly learning by doing to learning by simulating (Barreteau et al., 2001). The games' potential to facilitate institutional change is strongest when they are combined with communication (Balliet, 2010). We further acknowledge the potential of experimental games to complement innovation systems approaches which emphasize the co-evolution of innovation processes aligning technical, social, institutional and organizational dimensions (Hall, 2005). The games can give valuable insights to stimulate multi-stakeholder innovation platforms.

Our games facilitated a process of social learning which builds the actors' capacity to achieve joint solutions towards their goals of water management (Pahl-Wostl et al., 2007; Meinzen-Dick et al., 2016). Games for sustainability commonly serve two objectives: (i) create awareness of a specific problem, and (ii) encourage players to develop solutions (Rajabu, 2007; Hertzog et al., 2014; Flood et al., 2018). Accordingly, we created awareness among communities about the cooperation challenges related to water management and encouraged discussions on formulating effective management rules. This should give us

Research question 2. How can experimental games facilitate social learning among water managers?

\section{Research area and background information}

Research was carried out in Bhilwara district in Rajasthan state in India (Fig. 1). The district is situated in the Sub-Humid Southern Plain agro-climatic zone, where average rainfall is approximately $630 \mathrm{~mm}$
(Government of Rajasthan (GoR, 2018). Agriculture in the district is prone to strong climatic variations. Approximately four-fifth of the district's population depends on agriculture. Maize, mustard, black gram, sorghum, wheat, chilies and barley are the major crops grown. In 2016, 52 percent of Bhilwara's total net sown area of $4359 \mathrm{~km}^{2}$ was rainfed. Water harvesting structures irrigated only $31 \mathrm{~km}^{2}$ of agricultural land while wells irrigated $2138 \mathrm{~km}^{2}$ (Government of Rajasthan (GoR, 2018). There is, however, a link between water harvesting and wells. Often, tanks are not directly used for irrigation but they are critical for groundwater recharge. Poor management of water harvesting structures leads to widespread drying up of wells.

\section{Research methodology}

\subsection{General approach}

The research team first visited the project area in 2015 to improve the understanding of the challenges in water management. Focus group discussions (FGDs) were organized in arbitrarily selected villages with village members mobilized by the NGO partner Foundation for Ecological Security (FES) and the local administration. The discussions helped to clarify: (i) whether there really are coordination challenges related to village water infrastructure, (ii) in which fields institutions fail to address water related social dilemmas, (iii) the historical or current rules and norms farmers refer to, (iv) types of benefits perceived in relation to the infrastructure and (iiv) the costs and benefits of water infrastructure management. Together, this information helped us to design a game that was highly likely to support communities in developing rules to improve water infrastructure management.

We also report the results of a FGD with regional representatives of the FES, the Department of Agriculture and progressive farmers. One of the tasks of the FGD was to name the benefits and services provided by minor irrigation infrastructure. We asked the FGD participants to rate the excludability and subtractability of each of the benefits they had mentioned. Excludability refers to the costs of preventing a beneficiary from enjoying a benefit. Subtractability describes to which degree one beneficiary's enjoyment affects the possibility of other beneficiaries enjoying the same benefit (Ostrom, 2009; Falk et al., 2018). Substractability was rated on a three-point scale (no competition in use, moderate competition, and strong competition). Excludability was rated on a four-point scale (very easy to exclude others from use, easy to exclude, difficult to exclude, and very difficult to exclude). Perceptions on benefits related to water infrastructure management and their classification were recorded using an openly accessible online diagnostic tool for assessing ecosystem services (cmap.icrisat.ac.in/ges). The results of this assessment were graphically analyzed (Fig. 3).

For sampling, a list of villages in Bhilwara district was extracted from the official 2011 Census of the Government of India. Of a total of 316 villages, 30 with minor irrigation dams were randomly selected. Between February and March 2016, the sample villages were visited. Two days before the games were played, the project was introduced and ten people who play a critical role in agriculture, water and water infrastructure management were mobilized. Village leaders supported in mobilizing key community members with whom the games were played. Table 1 summarizes socio-economic characteristics of the sample households. Our sample was representative for rural Bhilwara in terms of age. There was, however, an over-representation of better educated males and an under-representation of Scheduled Caste (SC) members. This sample bias reflects the social reality in the research region, with well-educated men belonging to privileged sub-groups being the ones mainly making decisions on water management.

In order to observe the impact of the games, 7 out of the 30 sites were revisited in December 2017 to play the games again with community members. 


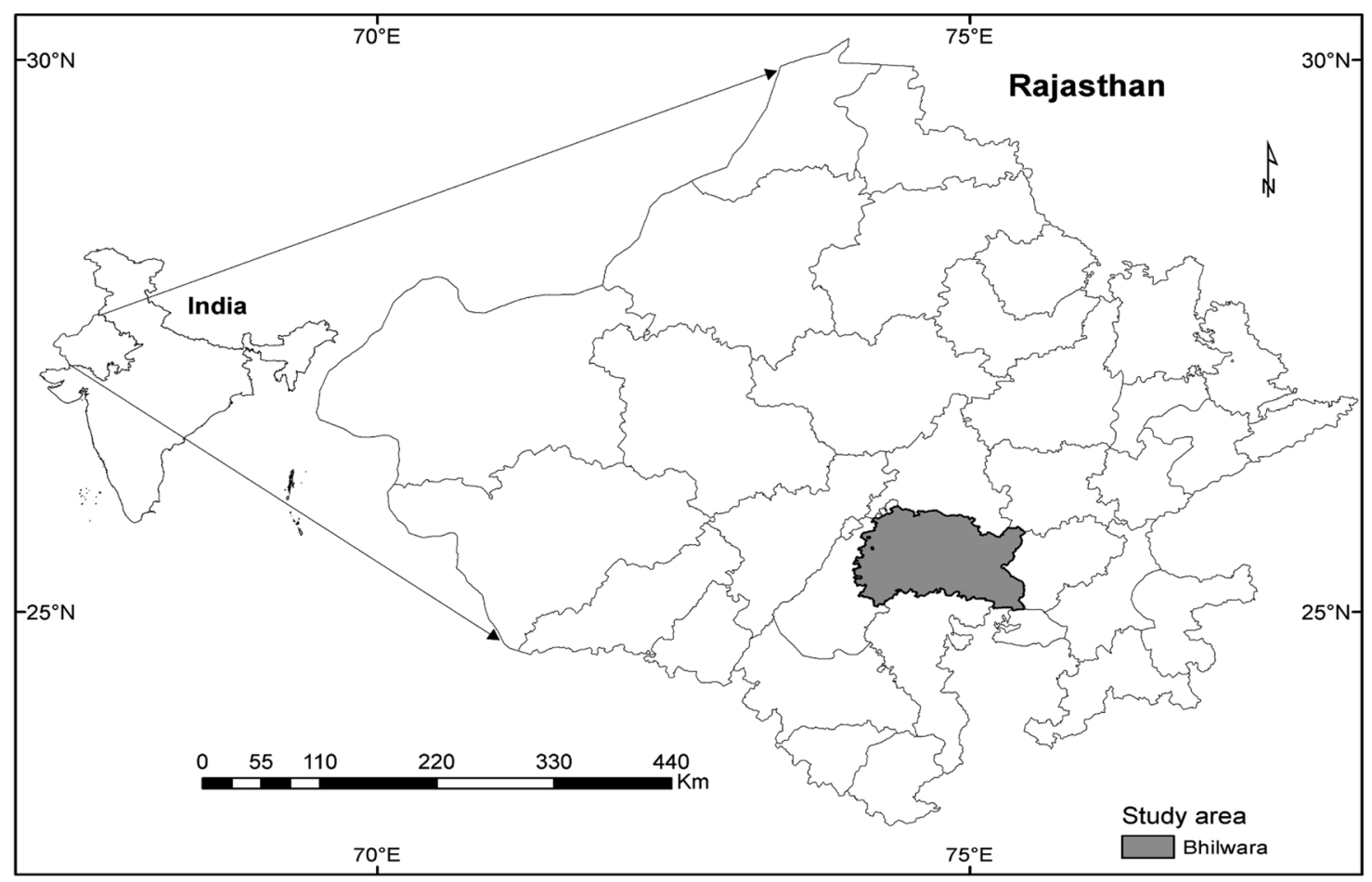

Fig. 1. Map of the research area greater insights and will eventually support social innovation through experimental games. Hence, our second question is.

\subsection{Experiment design}

We replicated the dam management challenges in a simplified manner using a framed public good experiment. We decided to focus on the provisioning action situations on the basis of stakeholder consultations. A non-linear pay-off function similar to the one in the irrigation games of Cardenas et al. (2008) and Janssen et al. (2011, 2012) was used. Pay-offs were adjusted to estimates of average maintenance costs of dams as well as typical income derived from dam water based on evaluations done by Singh et al. (2014).

At the start of each round, participants were provided with the same initial endowment of 5000 Play Rupees. All participants decided simultaneously and concealed which share of this endowment they wanted to invest in maintaining the dam. Decision cards were used for this purpose. The accumulated individual contributions determine the group earning as shown by an S-shaped pay-off function which was presented throughout the game as a table poster. The group earning was distributed equally among the players. Total earnings by an individual in a round were determined by this share of the group earnings from the dam, plus the amount of the initial endowment not invested.

We made incentivized payments in order to improve the reliability and validity of our games (Loomis, 2014). The accumulated individual Play Rupee earnings were exchanged at the rate of US\$ 0.015 per 1000 Play Rupees. The exchange rate was adjusted to generate expected earnings equivalent to one day's wages under the NREGA social employment scheme. In addition, each participant received US\$ 1.10 as a non-incentivized show-up fee which was paid out together with the incentivized payment.

Local field assistants were trained in facilitating the game. They explained the rules, conducted a quiz and test rounds and recorded the decisions on computers. The games were structured in three phases. Firstly, five baseline rounds were played with private decisions and without any communication. After playing these five rounds with anonymous decisions, we revealed the players' decision from round six onwards. In this phase, contributions and earnings were written on a large poster table visible to all. After each round, players could also discuss their experience in the game. The discussion was a critical element of our design as it allowed the players to start negotiations and propose rules. After round ten, the facilitators chose a game variation for each group based on its specific content of discussions. A suite of variations was prepared based on explorative assessments and pre-tests. The game variation was played for five additional rounds. The variation options are summarized below:

NREGA variation: Under the Mahatma Gandhi National Rural Employment Guarantee Act scheme, poor community members have the guaranteed right to work for a minimum number of days per month for a government set wage. The social employment scheme generates income for the poor and supports public work in the interest of communities. In this game variation, it is assumed that NREGA could be directed to maintain water infrastructure. For this to happen, individuals would need to lobby this interest at the Panchayat (local administration) level. Lobbying was costly and the game variation allowed de facto to reach higher group income levels with lower individual investments.

Table 1

Socio-economic attributes of the population of rural Bhilwara and those of the sample population (source: Population census of 2011 and own data).

\begin{tabular}{|c|c|c|}
\hline & Rural adult population of Bhilwara district & Study sample \\
\hline Average age & 37 & 35 \\
\hline Share of population with below primary education & $64 \%$ & $36 \%$ \\
\hline Share of population with above secondary education & $5 \%$ & $27 \%$ \\
\hline Male/female ratio & 0.99 & 1.77 \\
\hline Share of scheduled caste population & $17.5 \%$ & $7.3 \%$ \\
\hline
\end{tabular}


Development project variation: This game variation is simulating a common reason for poor dam maintenance. Irregular government repairs discourage farmers' collective action (Bouma, 2008). We assume that there is a one in six chance that the government or an international donor would be doing the maintenance work. If the donor is maintaining the dam, the players get the whole income but the money they have invested is gone. Nevertheless, if the donor does not step in, the income is calculated on the basis of the group's contribution.

Exclusion variation: After every round, the group can decide to exclude somebody from the dam, which eventually would mean the person loses her/his benefits for this round. We took into account the fact that it takes some effort to enforce this exclusion. Therefore, if any player gets excluded by the group, each of the other group members will have to pay 500 Play Rupees. The practice of excluding fellow farmers was found in one village during explorative field visits. It was reported that the group blocked a channel and removed a pump of a non-compliant farmer.

In order to answer our research questions, we recorded each players' decision during the game using entry forms on netbooks. We recorded the summaries of the discussions and additionally counted all discussion input by content categories. The latter was done on paper forms to enable quicker recording. Analyzing the content of the discussions allowed us to draw conclusions about the process and impact of social learning in the game (Flood et al., 2018).

The complete protocol of the game can be found at gamesforsustainability.org/India_village_dam_PG_game_ICRISAT_2016. pdf. The data set can be accessed under dx.doi.org/10.21421/D2/ MFT8ZD.

\section{Theoretical reflections}

The maximum group earning that could be achieved in our game design (171,000 Play Rupees) required that players collectively invest 45,000 Play Rupees. The Nash equilibrium would be, however, a strategy wherein individual players act selfishly and do not invest anything in the public good, i.e., keeping the full endowment in their private account. Empirical evidence barely confirms such theoretical predictions. Singleton and Taylor's (1992) concept of cooperation through "mutual vulnerability" offers an explanation for contributions above the Nash equilibrium. They define "mutual vulnerability" as "the condition of a group of actors each of whom values something which can be contributed or withheld by others in the group and can therefore be used as a sanction against that actor". In the case of water infrastructure maintenance by Rajasthan farmers, any player can contribute or withhold participation in cooperative infrastructure maintenance. The withholding of cooperation is a credible threat and can be used as a sanction.

We allowed communication as a realistic representation of the reallife situation, where neighbouring farmers meet regularly during daily activities. There is multiple evidence that even "cheap talk" successfully improves the self-organization of groups (for meta-analyses, see Balliet, 2010; Chaudhuri, 2011; Janssen et al., 2014). Face-to-face communication is particularly efficient to develop institutions. Communication can further create trust as players obtain information about each other's values and intensions (Ostrom, 2009). It supports cooperation since it enables receiving signals about the other's willingness to cooperate, creates a group identity, helps in developing joint strategies, voicing commitments and supports developing as well as enforcing shared norms (Balliet, 2010; Janssen et al., 2014). While it is not this study's objective to deepen the understanding of communication in experimental games, it was introduced given its potential to support social learning. It should be kept in mind that institutional capacity development was the critical motivation to play the game with Rajasthan farmers.

The transparency of individual contributions and earnings was meant to intensify group discussions and support, and thereby the development of rules. Moreover, in real life too, farmers are very much aware of the contributions of fellow farmers to group investments. There is empirical evidence that information which allows players to estimate the level of cooperation by others affects the level of cooperation (Janssen et al., 2014). People comply with social norms because they wish their actions to be approved. Social approval or disapproval does not have to be explicitly expressed. Often, the actor's anticipation of approval or disapproval constitutes already significant benefits or costs for her. Playing a simple public good experiment, Rege and Telle (2004) find evidence that people increase their cooperation levels when their decisions are made public. Soetevent (2005) observes that under specific conditions, church donations increase when neighbors can see how much a person is donating. Panagopoulos (2010) carried out an experiment where the names of either voters (pride treatment) or non-voters (shame treatment) in public elections were published in local newspapers. He finds evidence that shame in particular increased election turnouts while pride is effective only for subgroups in society.

Introducing the NREGA game variation does not change the theoretical prediction of zero investment. Theory would predict that no NREGA lobbying is done. From a group perspective, it would be beneficial if all players made use of the NREGA intervention and reduce their contributions by the amount which can be saved through it.

Given the zero contribution equilibrium, the development project game variation does not change theoretical predictions. Assuming contributions greater than zero, we expect that contributions decrease under this variation.

Economic theory predicts that the groups make no use of the costly exclusion opportunity (second-order public goods). Nevertheless, from experimental evidence, we know that participants provide such secondorder public goods even though doing so is costly (Ostrom, 1990; Ostrom et al., 1992; Fehr and Gächter, 2000). The willingness to apply costly sanctions can be explained by the concept of positive or negative intrinsic values such as joy or regret (Ostrom, 2009). Sanctioning does not need to produce material revenues if it is based on the intrinsic belief in the rightness of an action (Smith, 1759). Fehr and Gächter (2000) as well as Falk et al. (2005) also argue that whether or not participants sanction each other is based on their motivation to harm those who are perceived as behaving unfairly.

\section{Results}

\subsection{Baseline results}

The baseline round was the most controlled part of our game which can be compared with results of other experiments. Average investments in the baseline phase were 2965 Play Rupees ( $\sigma=1638$ ), which is almost 60 percent of the individual endowments. Only 2.3 percent of observations conformed to the Nash strategy of zero contribution. Almost 20 percent of the observations had investment levels above 4500 Play Rupees which would lead to optimal group outcomes if all members invested this amount. Nevertheless, the optimal group investment level was never reached in the first round.

We estimated an OLS model explaining the investment in the very first decisions which had not yet been influenced by the game dynamics, communication or social information (Appendix A). We see that youth, better educated people and scheduled caste members invest more. The history of a watershed project having been implemented did not have an impact on the decisions.

We used hierarchical Mixed-effects models with standard errors clustered by groups to analyze the game dynamics. This tool allowed us to control for variables on different scales. We considered individualcontext layer and group-context layer information. For individualcontext layer information, we included socio-economic indicators such as age, education level and being a scheduled caste member. For the group-context layer, we included whether there had been a watershed 
Table 2

Hierarchical Mixed effects models explaining the individual investments in the rounds without communication and social information (coefficients with clustered standard errors in parentheses).

\begin{tabular}{|c|c|c|}
\hline & $\begin{array}{l}\text { Model } 1 \text { - } \\
\text { only } 2016 \text { data }\end{array}$ & $\begin{array}{l}\text { Model } 2 \text { - } \\
\text { including } 2017 \text { data }\end{array}$ \\
\hline Game round & $-55.13(33.99)$ & $-53.10(33.27)$ \\
\hline Sex $(0=$ male, $1=$ female $)$ & $-22.27(196.79)$ & $-14.51(171.81)$ \\
\hline Age & $6.60(6.47)$ & $6.55(6.08)$ \\
\hline ln of Education level & $518.15^{* * k}(175.80)$ & $386.35^{*}(186.63)$ \\
\hline Watershed project implemented at site & $-188.36(150.04)$ & $-133.62(148.94)$ \\
\hline Av. investment of other group members in previous round & $0.34^{* \star *}(0.12)$ & $0.30 "(0.12)$ \\
\hline Survey year $(0=2016,1=2017)$ & & $-965.35^{* *}(344.14)$ \\
\hline Constant & $1470.03^{* *}(553.64)$ & $1676.90^{* / 16}(517.46)$ \\
\hline Site random-effects parameter & $4.62(9.68)$ & $5.29^{\prime \prime}(2.42)$ \\
\hline Individual random-effects parameter & $7.02^{* * *}(0.08)$ & $7.03^{* * *}(0.06)$ \\
\hline Residual random-effects parameter & $7.05 * * *(0.03)$ & $7.04 * * *(0.03)$ \\
\hline Observations & 1200 & 1289 \\
\hline
\end{tabular}

$* p<0.05$.

$* * p<0.01$.

project implemented in the village and the social network density of relatives in the group.

The analysis of rounds two to five (Table 2) which were undisturbed by communication and social information revealed that only the impact of the education level remains. More important than age, sex and caste became the game dynamic expressed by the average investment of other players in the previous round. At the same time, the individual random effects parameter was highly significant indicating a high variability in individual coefficients from the mean fixed effects coefficient.

Players who played the game twice invested in the baseline round significantly less in 2017 than in 2016 (Mann-Whitney test $z=5.72$, Prob $>|z|=0.000$, Table 2).

\subsection{Introducing game variations}

With the introduction of communication and revealing social information, the average investments increased to 3499 Play Rupees $(\sigma=1562)$, which is approximately 70 percent of the individual endowments (Fig. 2). The optimal group investment level of 45,000 Play Rupees was reached in 10 percent of the observations.

The models including all game rounds (Table 3 ) confirm that the introduction of communication and social information significantly increased contributions. The expectation that the government or other donors should repair the village infrastructure was very often mentioned in the discussion and the development project variation was therefore played in 10 out of 30 groups. There was no decrease in investments in this game variation.

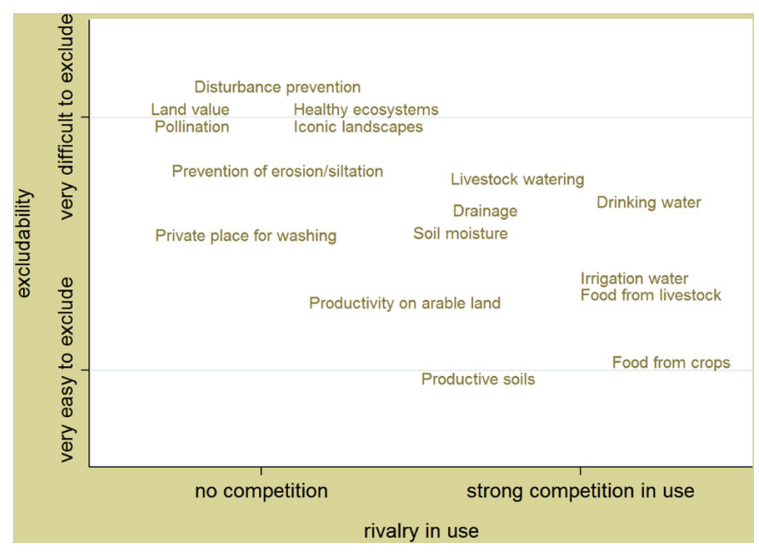

Fig. 3. Ecosystem services linked to minor village dams mentioned in stakeholder meeting and classified according to the typology of goods.

The NREGA scheme was mentioned in at least 26 percent of the groups during the discussions and consequently played with eight groups. The players decreased their investments to on average 2540 Play Rupees $(\sigma=1059)$. All players made 100 percent use of the NREGA opportunity. The average earnings were highest under this variation with a low standard deviation. What was striking was that in more than half of the observations, players paid higher amounts than was necessary to achieve the group optimum given that all players used NREGA and that all players paid this "optimum" amount. Despite this,

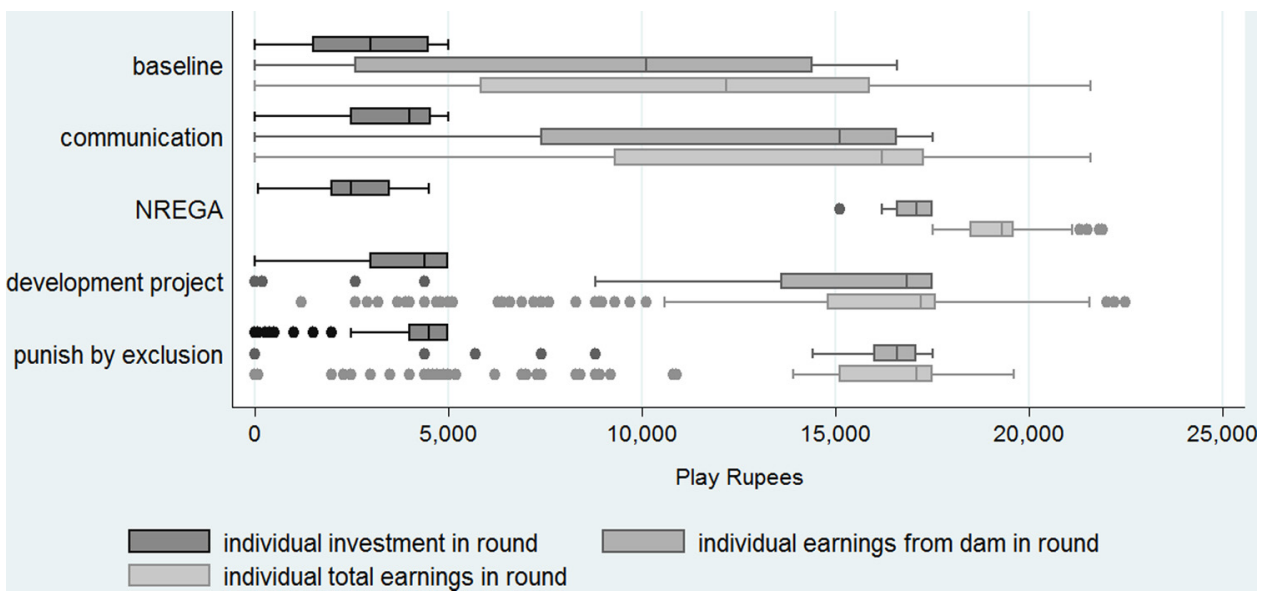

Fig. 2. Boxplot of individual contributions, game earnings from dam investments and total earnings by game variations. 
Table 3

Mixed-effects regression results over all rounds explaining individual amounts invested (coefficients with standard errors in parentheses.

\begin{tabular}{|c|c|c|}
\hline Game variables & Model 3 - only 2016 & Model $4-2016$ and 2017 \\
\hline Game round & $17.17(15.40)$ & $22.26(14.74)$ \\
\hline Survey year $(0=2016,1=2017)$ & & $-680.08^{*}(298.75)$ \\
\hline Average investment of other group members in previous round & $0.17^{* * * *}(0.06)$ & $0.23^{* * * *}(0.07)$ \\
\hline \multicolumn{3}{|l|}{ Game variations } \\
\hline Communication and social information & $469.34^{* k * *}(126.78)$ & $462.48^{* \star * *}(114.42)$ \\
\hline NREGA (lobbied external support) & $-1074.09^{k+k \cdot k}(192.42)$ & $-1027.69^{k+1 \times k}(190.31)$ \\
\hline Development project (random external support & $172.91(202.14)$ & $86.07(187.95)$ \\
\hline Punish by exclusion & $722.10^{* * * * 1}(143.01)$ & $594.71^{* * * *}(145.72)$ \\
\hline Punish by fine & & $1093.77^{\text {*k*k }}(309.50)$ \\
\hline Frequency of being sanctioned & $-1056.11^{* * * * *}(181.45)$ & $-998.20^{* * * *}(164.19)$ \\
\hline \multicolumn{3}{|l|}{ Individual-level variables } \\
\hline Sex $(0=$ male, $1=$ female $)$ & $38.65(108.03)$ & $-73.29(115.41)$ \\
\hline Age & $2.10(3.68)$ & $3.79(3.73)$ \\
\hline ln of Education level & $174.03(94.27)$ & $106.71(114.92)$ \\
\hline Member of scheduled caste & $-43.96(114.17)$ & \\
\hline \multicolumn{3}{|l|}{ Group-level variables } \\
\hline Watershed project implemented at site & $-82.14(128.99)$ & $-45.09(133.64)$ \\
\hline Network density of individual social relations & $-26.52(38.84)$ & \\
\hline Constant & $2150.83^{* * k * k}(288.95)$ & $1943.52^{* * * *}(257.52)$ \\
\hline Site Random-effects Parameters & $5.58^{* * * *}(0.30)$ & $5.55^{* * *}(0.29)$ \\
\hline Individual Random-effects Parameters & $6.33^{k+k \times k}(0.10)$ & $6.36^{* * * *}(0.09)$ \\
\hline Residual Random-effects Parameters & $7.16^{\text {tikn }}(0.03)$ & $7.18^{* * * *}(0.03)$ \\
\hline Number of players & 300 & 348 \\
\hline Observations & 4300 & 4762 \\
\hline
\end{tabular}

$$
\begin{aligned}
& * \mathrm{p}<0.1 . \\
& * * \mathrm{p}<0.05 \\
& * * * \mathrm{p}<0.01)
\end{aligned}
$$

only 15 percent of the cases saw an actual overinvestment at the group level. This indicates that a large share of the players was making extra investments in order to compensate for expected low investments of other group members.

The call for punishment and exclusion was strong in groups with persistent free-riders. Wilcoxon rank-sum test confirms significantly more frequent zero contributions in these groups before the game variation was introduced. The variation was played in eight groups and significantly increased the investments. At the same time, being excluded in previous rounds made players reduce their contributions even further rather than cooperating with the group. Rank-sum tests show no significant change in zero contributions before and after the exclusion opportunity was introduced in these groups.

Better educated players made overall higher contributions but reduced them as soon as communication and social information was introduced. We observed no impacts of other socio-economic controls on the contributions throughout the games - apart from the aforementioned pattern for the decision in the first round. Players who belonged to communities where watershed projects had been implemented showed no strong willingness to cooperate. Our models show highly significant random-effects parameters indicating strong differences across individuals and sites.

Moreover, an analysis of all game rounds indicates that players who played the game twice invested significantly less in 2017 than in 2016 (Table 3: Models 4).

\subsection{Analyses of game discussion}

The players intensively use of the opportunity to communicate (Table 4). Please take into account that for instance two contributions were counted if a player raised a complaint and proposed a rule within one discussion statement. Arguments were most often counted, followed by agreements to rules as well as rule proposals. The models in Table 5 indicate that men raised their voices more often as well as better educated and older participants. Scheduled caste members participated equally in the discussions.
Table 4

Absolute frequency of interactions during game discussions.

$\begin{array}{ll}\text { Individual proposed rule } & 1455 \\ \text { Individual agreed to rule } & 1547 \\ \text { Individual rejected rule } & 89 \\ \text { Individual argued } & 3062 \\ \text { Individual praised } & 144 \\ \text { Individual complained } & 140 \\ \text { Individual proposed punishment } & 67 \\ \text { Individual proposed reward } & 25 \\ \text { Unconnected communication } & 278 \\ \text { Total interactions } & 6807\end{array}$

Table 5

Mixed-effects regression results of individual contributions to the discussion by rounds (2016 only); (coefficients with standard errors in parentheses.

\begin{tabular}{lll} 
& $\begin{array}{l}\text { Model } 5 \\
\text { Total interactions }\end{array}$ & $\begin{array}{l}\text { Model } 6 \\
\text { Individual proposed } \\
\text { rule }\end{array}$ \\
\hline Game round & $0.00(0.03)$ & $-0.01^{* *}(0.01)$ \\
Group investment in previous round & $-0.00(0.00)$ & $-0.00(0.00)$ \\
Sex (0 = male, 1 = female) & $-0.72^{* * * * *}(0.18)$ & $-0.27^{* * * * *}(0.06)$ \\
Age & $0.01(0.01)$ & $0.01^{* *}(0.00)$ \\
ln of Education class & $0.67^{* * * *}(0.19)$ & $0.28^{* * * *}(0.07)$ \\
Member of Scheduled Caste & $-0.54^{*}(0.26)$ & $-0.13(0.10)$ \\
Watershed project implemented at & $-0.05(0.07)$ & $0.02(0.02)$ \\
$\quad$ site & $-0.05(0.07)$ & $0.02(0.02)$ \\
Network density of individual social & & \\
$\quad$ relations & $1.72^{* * * * *}(0.46)$ & $0.30^{* *}(0.15)$ \\
Constant & $0.06(0.14)$ & $-1.47^{* * * *}(0.19)$ \\
Site Random-effects Parameter & $0.19^{* *}(0.09)$ & $-0.73^{* * * * *}(0.10)$ \\
Individual Random-effects Parameter & $0.35^{* * * *}(0.07)$ & $-0.59^{* * * * *}(0.06)$ \\
Residual Random-effects Parameter & 300 & 300 \\
Number of players & 3100 & 3100 \\
Observations & &
\end{tabular}

$$
* \mathrm{p}<0.1
$$$$
* * * \mathrm{p}<0.01) \text {. }
$$ 
Table 6

The most frequently discussed topics.

\begin{tabular}{ll}
\hline Discussion topic & $\begin{array}{l}\text { Absolute frequency of being mentioned } \\
\text { out of } 30 \text { sessions }\end{array}$
\end{tabular}

\begin{tabular}{ll}
\hline Expressed need to cooperate & 16 \\
Proposed rule of equal maintenance contribution & 15 \\
$\begin{array}{l}\text { Expressed call for external (esp. government) help } \\
\text { Stressed the importance of equity in the community }\end{array}$ & 15 \\
$\begin{array}{l}\text { Proposed to sanction uncooperative community members } \\
\text { Call to find solutions within the community rather than waiting }\end{array}$ & 12 \\
$\quad$ for external help & 10 \\
$\begin{array}{l}\text { Highlighted that poor water infrastructure maintenance is a } \\
\text { problem in the community }\end{array}$ & 9 \\
$\begin{array}{l}\text { Highlighted the need to talk about the problem } \\
\text { Drew strong parallels between the game and the real life } \\
\quad \text { experience of dam maintenance }\end{array}$ & 7 \\
$\begin{array}{l}\text { Related the game to other cooperation challenges but dam } \\
\text { maintenance }\end{array}$ & 7 \\
$\begin{array}{l}\text { Expected the local government to solve the problem } \\
\text { Saw the potential to use the NREGA social employment program } \\
\text { to address the problem }\end{array}$ & 5 \\
$\begin{array}{l}\text { Highlighted the potential of traditional practices to contribute to } \\
\text { solving the problem }\end{array}$ & 4 \\
\hline
\end{tabular}

We observed no strong impact of the game dynamics on the communication patterns. The discussion content did not significantly change over the rounds. The models in Appendix $\mathrm{B}$ indicate that whenever players agreed to rules, they were making significantly higher contributions and enjoyed significantly higher earnings. Players who proposed a punishment made higher contributions in the next round.

We recorded only summaries of the discussions and will therefore provide only a rough content analyses. Table 6 lists the most frequently discussed topics. Approximately half of the communities clearly expressed a severe problem with water infrastructure maintenance. The need to cooperate was the most often expressed response to this situation. The third most frequently made statement was the call for government investments in community water management. At the same time, there were many voices warning that the community will lose by waiting for somebody else to solve their problems. There was a great variety of institutional mechanisms mentioned ranging from the importance of holding meetings, expecting the panchayat to take responsibility, making use of the NREGA social employment scheme, or calling on the help of NGOs. Players proposed sanctions on uncooperative behavior in approximately half of the discussions. Historical institutional practices were mentioned in very few cases. Whatever the institutional solution to be found, equality was a top priority value to be taken into account.

Beyond understanding the degree to which the discussion influenced the game, we also wanted to estimate whether the game supported social learning. We can see that many communities acknowledged the real-life problem, expressed the need to address it and proposed solutions that are in the realm of the community.

\subsection{Ecosystem service assessment}

Fig. 3 shows that regional representatives of FES, the Department of agriculture and progressive farmers named a considerable diversity of benefits related to minor irrigation infrastructure. They made specific mention of benefits in the field of private and public goods. Doing the same exercise with farmers produced a stronger weight towards locally enjoyed private goods. Groundwater recharge as a commonly expected benefit from rainwater harvesting by dams (Glendenning et al., 2012) has not been directly mentioned.

\section{Discussion}

Players in our game were relatively cooperative, which is common in irrigation experiments (Janssen et al., 2011; Javaid and Falk, 2015). They also showed the commonly observed downward trend in investments over the rounds (Fehr and Gächter, 2000; Chaudhuri, 2011) even though it was not significant when controlling for the lag of other players' contributions.

Introducing social information and communication was highly effective in increasing cooperation levels. An analysis of the discussion content shows that the players mainly used this opportunity to coordinate. They certainly also received signals about other's willingness to cooperate (Javaid and Falk, 2015; Balliet, 2010). The later effect was strengthened through the disclosure of everybody's contributions. Croson and Shang (2008) found evidence that learning about other people's behavior influences beliefs about social norms, which thereby affects one's own behavior. Mittone and Ploner (2011) observed that knowing to be observed has an even stronger effect. Being observed reinforces internalized norms through moral and social enforcement (Falk et al., 2012). Our players used the communication only to a very limited degree to enforce rules through social sanctions. Only four percent of the discussion contributions were related to praise or blame.

At the majority of sites, proposals for material sanctions came up sooner or later. The groups who played the game variation where fellow players could be sanctioned had higher overall investment levels. It seems that the groups felt more confident with the possibility to sanction and were therefore willing to invest more. At the same time, being sanctioned did not motivate infringers to cooperate with the rest of the group. Additional mechanisms are needed to motivate free-riders to cooperate. In the real world, special attention can be paid to private good ecosystem services as excluding from their enjoyment is a common sanctioning instrument.

At the same time, acknowledging common pool resources provided by rainwater harvesting (Glendenning and Vervoort, 2010, 2011, Glendenning et al., 2012) but experienced beyond the local scale indicates that dam governance requires coordination at a higher scale. This can even economically justify regular government support to minor irrigation infrastructure maintenance.

The fact that older and better educated men contributed more strongly to the discussion can probably be related to social norms and perceived differentiation. It affects cooperation within communities. Our results confirm the need to facilitate decision making processes which encourage women, youth and the less educated to express and defend their interests. The role of general education has to be emphasized. Less educated community members made lesser contributions in the very first round of the game which most strongly reflects internalized cooperation patterns. While we did not observe that they made lower investments throughout the game, they participated significantly less in the discussion.

In response to our first research question, it is confusing that the high investment levels in the game did not correspond to the absent actual investment on water infrastructure. Does this mean that our methodology does not allow us to answer our first research question? The games provided valuable insights into how community members make water management choices (Meinzen-Dick et al., 2016), especially in terms of responses to interventions and communication patterns. Hertzog et al. (2014) argue that games allow players to experiment with more daring actions (see also Speelman et al., 2017). They are encouraged to think out of the box without taking any actual risk. We also observed a few times that better educated players were extraordinarily uncooperative. The team spoke to some of them after the game. One woman explained that she wanted to use the game to demonstrate to the community members how they act in real life. She used the game to play a role with the intention of encouraging discussion while the role might not have represented her actual behavioral pattern. 
Another positive view on this is that we developed an instrument that supported social learning. What lessons did we learn with regard to our second research question? One way of estimating the degree of social learning is to observe the dynamics in a game (Flood et al., 2018). Unfortunately, we neither observed an increase in contributions over the baseline rounds nor over the rounds when communication was allowed. Meinzen-Dick et al. (2018) observed that players made higher contributions when the games were played with them a second time a few months later. To our great disappointment, the players in our study contributed less during our second visit 20 months later.

Can we conclude that the players did not learn in the process? Direct feedback is also an accepted way of measuring game impacts (Flood et al., 2018) and many farmers opined that playing the game helped the group recognize and collectively discuss their problems of common water infrastructure maintenance. The discussions showed that the players connected the game to their real-life experiences. This implies reflexive learning impacts (Flood et al., 2018). They highlighted challenges but gave also examples where cooperation in the community was working well.

Interventions related to natural resource governance require a complexity to be effective, which makes it difficult to measure their impact. For instance, while speaking about introducing a new irrigation technology or an insurance instrument, everyone immediately understands what impact this can create. On the contrary, talking about institutional change and governance is a much fuzzier space (Woodhill, 2010). Links to measurable impacts are typically indirect and happen over long time frames. This is one reason why donors and governments in India still focus on searching for technical water management solutions (Pahl-Wostl et al., 2008).

Flood et al. (2018) highlight that the impact of games on social learning is likely to be moderate in a one-off engagement. We probably made a contribution, but generating a strong impact calls for an approach that is embedded into a larger intervention framework (Meinzen-Dick et al., 2018). There is a need for greater clarity on how experimental approaches in combination with other methods can efficiently facilitate social learning. We see, for instance, the potential to integrate the approach into stakeholder innovation platform (IP) processes. The games can effectively trigger communities to develop governance innovations related to common water infrastructure. The IP's underlying philosophy is to engage diverse actors and create synergies to find solutions collectively. The games could quickly visualize the benefits of cooperation to water users association (WUA) and public and private actors and motivate them to develop governance innovations. At the same time, IPs provide an ecosystem for persistently motivating members' to collectively discuss their problems of common water infrastructure maintenance. IPs often have broader objectives, and low-cost facilitation tools like games are important to increase the efficiency of their processes. This again is important to improve the chances of scaling IP processes.

\section{Conclusion}

The relevance of our paper beyond the specific case context lies in the lessons learnt regarding the potential of experimental games to facilitate social learning. Our study demonstrated how experimental games can be used to facilitate a participatory process where communities identify required governance interventions fitting into their context. It further demonstrated the importance of a communication environment which encourages the young, the less educated and women to actively participate in decision making. In this way the games can bring to the table diverse power constellations in a relatively safe space.

The participants' discussions during the game as well as the game dynamics indicate that people learned in the game process. Nevertheless, our study does not tell us whether this learning actually led to behavioral change. We see the need to make stronger efforts to measure impact of similar approaches along a theory of change. So far, the impact of games is mainly measured in recording knowledge and attitude changes directly after the session (Flood et al., 2018). We need to examine whether and when this change in knowledge changes institutions, behavior and eventually improves sustainability outcomes. At the same time, we see the danger of adapting the games in ways which do not explore their full potential to achieve impact in order to measure their impact in a reliable way. New methodologies are needed to address this trade-off.

\section{Acknowledgments}

The research was carried out under the CGIAR Research Program on Water, Land and Ecosystems (WLE) and was supported by the CGIAR Research Program on Policies, Institutions and Markets (PIM). We thank the Foundation for Ecological Security as well as the Institute of Development Studies/Jaipur for their support in implementing the study. The authors especially acknowledge all the participating communities for their time, assistance and hospitality. We thank the assistants who contributed to the study, in particular, Sudeep Pithani. Comments from Victoria Reyes García, Michael Hauser, Peter Droogers and an anonymous reviewer helped us to substantially improve the paper.

Appendix A. OLS model explaining the individual investments in the first round (coefficients with clustered standard errors in parentheses; * $\mathrm{p}<0.05, * * \mathrm{p}<0.01, * * * \mathrm{p}<0.001$.)

\begin{tabular}{ll}
\hline & $\begin{array}{l}\text { Model } 1- \\
\text { only } 2016 \text { data }\end{array}$ \\
\hline Sex $(0=$ male, $1=$ female $)$ & $-334.61(184.56)$ \\
Age & $-14.63^{*}(7.24)$ \\
ln of Education level & $546.36^{* *}(172.25)$ \\
Member of scheduled caste & $649.16^{*}(314.73)$ \\
Watershed project implemented at site & $-98.01(172.79)$ \\
Network density of individual social relations & $87.98(47.88)$ \\
Constant & $3250.82^{* * *}(424.79)$ \\
Observations & 300 \\
\hline
\end{tabular}


Appendix B. Mixed-effects regression results over all rounds explaining individual amounts invested (coefficients with standard errors in parentheses; " $\mathrm{p}<0.1,{ }^{* *} \mathrm{p}<0.05,{ }^{* * *} \mathrm{p}<0.01$ )

\begin{tabular}{|c|c|c|}
\hline Game variables & Model A1; 2016 only, including discussion variables & Model A2; 2016 and 2017, including discussion variables \\
\hline Game round & $10.92(16.05)$ & $13.94(15.31)$ \\
\hline Survey year $(0=2016,1=2017)$ & & $-776.57 *(312.22)$ \\
\hline $\begin{array}{l}\text { Average investment of other group members in previous round } \\
\text { Game variations }\end{array}$ & $0.16^{*}(0.06)$ & $0.21^{* * *}(0.07)$ \\
\hline Communication & $395.54^{* *}(126.73)$ & $380.56^{* * * *}(111.12)$ \\
\hline NREGA & $-1120.08^{* \ldots * k}(205.35)$ & $-1069.56^{* * * *}(206.34)$ \\
\hline Development project & $163.26(208.29)$ & $85.25(197.89)$ \\
\hline Punish by exclusion & $685.60^{\text {**** }}(146.00)$ & $559.59^{* * * * k}(149.24)$ \\
\hline Fine & & $1150.21^{* * * *}(324.68)$ \\
\hline Frequency of being sanctioned & $-1034.89^{k * * *}(170.58)$ & $-997.11^{\text {*⿻*k }}(148.19)$ \\
\hline \multicolumn{3}{|l|}{ Individual-level variables } \\
\hline Sex $(0=$ male, $1=$ female $)$ & $41.70(108.98)$ & $-73.37(116.47)$ \\
\hline Age & $2.10(3.68)$ & $3.73(3.77)$ \\
\hline ln of Education level & $172.03(99.00)$ & 104.77 (119.69) \\
\hline Member of scheduled caste & $-46.15(114.95)$ & \\
\hline \multicolumn{3}{|l|}{ Group-level variables } \\
\hline Watershed project implemented at site & $-99.53(130.38)$ & $-55.30(136.85)$ \\
\hline Network density of individual social relations & $-24.53(41.05)$ & \\
\hline \multicolumn{3}{|l|}{ Communication records in discussion before this round's decision } \\
\hline Proposed rule & $11.88(35.15)$ & $23.03(35.33)$ \\
\hline Agreed to rule & $214.67^{* *}(68.69)$ & $244.60^{* * * * k}(62.64)$ \\
\hline Rejected rule & $-20.25(112.17)$ & $87.30(118.60)$ \\
\hline Argued & $8.47(32.83)$ & $1.90(29.22)$ \\
\hline Proposed punishment & $348.00^{\text {***** }}(96.77)$ & $335.09^{* * *}(103.06)$ \\
\hline Unconnected statements & $262.49^{*}(114.70)$ & $312.12^{\text {*** }}(103.46)$ \\
\hline Constant & $2225.29^{* * k * k}(285.35)$ & 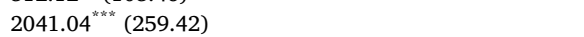 \\
\hline Site Random-effects Parameters & $5.67^{* * * * k}(0.30)$ & $5.65^{\text {*⿻*k }}(0.29)$ \\
\hline Individual Random-effects Parameters & $6.33^{* * * *}(0.10)$ & $6.37^{* * * k}(0.09)$ \\
\hline Residual Random-effects Parameters & $7.16^{\text {***k}}(0.03)$ & $7.17^{* * * *}(0.03)$ \\
\hline Number of players & 300 & 348 \\
\hline Observations & 4300 & 4762 \\
\hline
\end{tabular}

\section{References}

Balliet, D., 2010. Communication and cooperation in social dilemmas: a meta-analytic review. J. Conflict Resolut. 54, 39-57.

Balooni, K., Kalro, A.H., Kamalamma, A.G., 2008. Community initiatives in building and managing temporary check-dams across seasonal streams for water harvesting in South India. Agric. Water Manag. 95 (12), 1314-1322.

Barreteau, O., Bousquet, F., Attonaty, J.M., 2001. Role-playing games for opening the black box of multi-agent systems: method and lessons of its application to Senegal River valley irrigated systems. Journal of Artificial Societies and Social Simulations 4 (2), 5 .

Barreteau, O., Antona, M., D’Aquino, P., Aubert, S., Boissau, S., Bousquet, F., Daré, W.S., Etienne, M., Le Page, C., Mathevet, R., Trébuil, G., 2003. Our companion modelling approach. J. Artif. Soc. Soc. Simul. 6 (1).

Becu, N., Neef, A., Schreinemachers, P., Sangkapitux, C., 2008. Participatory computer simulations to support collective decision-making: potential and limits of stakeholder involvement. Land Use Policy 25 (4), 498-509.

Bouma, J.A., 2008. Voluntary Cooperation in the Provision of a Semi-public Good: Community-based Soil and Water Conservation in Semi-arid India (No. 07173aaba40b-4b0b-bc44-91c3d4c7bf57). Tilburg University, School of Economics and Management.

Campbell, L.M., Vainio-Mattila, A., 2003. Participatory development and communitybased conservation: Opportunities missed for lessons learned? Hum. Ecol. 31 (3), 417-437.

Cardenas, J.C., Janssen, M., Bousquet, F., 2008. Dynamics of Rules and Resources: Three New Field Experiments on Water, Forests and Fisheries. Handbook on Experimental Economics and the Environment.

Chaudhuri, A., 2011. Sustaining cooperation in laboratory public goods experiments: a selective survey of the literature. Exp. Econ. 14 (1), 47-83.

Cox, M., Arnold, G., Tomás, S.V., 2010. A review of design principles for communitybased natural resource management. In: In: Cole, D.H., McGinnis, M.D. (Eds.), Elinor Ostrom and the Bloomington School of Political Economy: Resource Governance, vol. 2 Lexington Books.

Croson, R., Shang, J., 2008. The impact of downward social information on contribution decisions. Exp. Econ. 11 (3), 221-233.

Falk, A., Fehr, E., Fischbacher, U., 2005. Driving forces behind informal sanctions. Econometrica 73 (6), 2017-2030.

Falk, T., Bock, B., Kirk, M., 2009. Polycentrism and poverty: experiences of rural water supply reform in Namibia. Water Alternatives 2 (1), 115.

Falk, T., Vollan, B., Kirk, M., 2012. Analysis of material, social, and moral governance in natural resource management in southern Namibia. Int. J. Commons 6, 271-301.
Falk, T., Lohmann, D., Azebaze, N., 2016. Congruence of appropriation and provision in collective water provision in Central Namibia. Int. J. Commons 10 (1), 71-118.

Falk, T., Spangenberg, J.H., Siegmund-Schultze, M., Kobbe, S., Feike, T., Kuebler, D., Settele, J., Vorlaufer, T., 2018. Identifying governance challenges in ecosystem services management - conceptual considerations and comparison of global forest cases. Ecosyst. Serv. 32, 193-203.

Fehr, E., Gächter, S., 2000. Cooperation and punishment in public goods experiments. Am. Econ. Rev. 90, 980-994.

Flood, S., Cradock-Henry, N.A., Blackett, P., Edwards, P., 2018. Adaptive and interactive climate futures: systematic review of 'serious games' for engagement and decisionmaking. Environ. Res. Lett. 13 (6).

Garg, K.K., Karlberg, L., Barron, J., Wani, S.P., Rockström, J., 2011. Assessing impact of agricultural water interventions at the Kothapally watershed, Southern India. Hydrol. Process. 26 (3), 387-404.

Garg, K.K., Wani, S.P., Barron, J., Karlberg, L., Rockström, J., 2012. Up-scaling potential impacts on water flows from agricultural water interventions: opportunities and trade-offs in the Osman Sagar catchment, Musi sub-basin, India. Hydrol. Process. 27 (26), 3905-3921.

Gleick, P.H., 1998. Water in crisis: paths to sustainable water use. Ecol. Appl. 8 (3), 571-579.

Glendenning, C.J., Vervoort, R.W., 2010. Hydrological impacts of rainwater harvesting (RWH) in a case study catchment: The Arvari River, Rajasthan, India. Part 1: Fieldscale impacts. Agric. Water Manag. 98 (2), 331-342.

Glendenning, C.J., Vervoort, R.W., 2011. Hydrological impacts of rainwater harvesting (RWH) in a case study catchment: The Arvari River, Rajasthan, India: Part 2. Catchment-scale impacts. Agricultural Water Management 98 (4), 715-730.

Glendenning, C.J., Van Ogtrop, F.F., Mishra, A.K., Vervoort, R.W., 2012. Balancing watershed and local scale impacts of rain water harvesting in India-a review. Agric. Water Manag. 107, 1-13.

Government of Rajasthan (GoR), 2000. The Rajasthan Farmers' Participation in Management of Irrigation Systems Act No. 21 of 2000.

Government of Rajasthan (GoR), 2018. Rajasthan Agricultural Statistics at a Glance. Commissionerate of Agriculture, Jaipur/India.

Gurung, T.R., Bousquet, F., Trébuil, G., 2006. Companion modelling, conflict resolution, and institution building: sharing irrigation water in the Lingmetuychu watershed. Bhutan. Ecology and Society 11 (2), 36.

Guyot, P., Honiden, S., 2006. Agent-based participatory simulations: merging multi-agent systems and role-playing games. Journal of Artificial Societies and Social Simulations 9 (4).

Hall, A.J., 2005. Capacity development for agricultural biotechnology in developing countries: an innovation systems view of what it is and how to develop it. J. Int. Dev. 19 (5), 611-630. 
Hertzog, T., Poussin, J.C., Tangara, B., Kouriba, I., Jamin, J.Y., 2014. A role playing game to address future water management issues in a large irrigated system: experience from Mali. Agric. Water Manag. 137, 1-14.

Janssen, M.A., Anderies, J.M., Joshi, S.R., 2011. Coordination and cooperation in asymmetric commons dilemmas. Exp. Econ. 14, 547-566.

Janssen, M.A., Bousquet, F., Cardenas, J.C., Castillo, D., Worrapimphong, K., 2012. Field experiments of irrigation dilemmas. Agric. Syst. 109, 65-75.

Janssen, M., Tyson, M., Lee, A., 2014. The effect of constrained communication and limited information in governing a common resource. Int. J. Commons 8 (2), 617-635.

Javaid, A., Falk, T., 2015. Incorporating local institutions in irrigation experiments: evidence from rural communities in Pakistan. Ecol. Soc. 20 (2), 28

Joshi, P.K., Jha, A.K., Wani, S.P., Joshi, L., Shiyani, R.L., 2005. Meta-analysis to Assess Impact of Watershed Programme and People's Participation. Research Report no. 8. International Crops Research Institute for the Semi-arid Tropics, Patancheru. India and Asian Development Bank, Manila, the Philippines.

Karlberg, L., Garg, K.K., Barron, J., Wani, S.P., 2015. Impacts of agricultural water interventions on farm income: an example from the Kothapally watershed, India. Agric. Syst. 136, 30-38.

Kerr, J., 2002. Watershed development, environmental services, and poverty alleviation in India. World Dev. 30 (8), 1387-1400.

Kumar, S., Ramilan, T., Ramarao, C.A., Rao, Ch., Srinivasa, Whitbread A., 2016. Farm level rainwater harvesting across different agro climatic regions of India: assessing performance and its determinants. Agric. Water Manag. 176 (2016), 55-66.

Loomis, J.B., 2014. Strategies for overcoming hypothetical bias in stated preference surveys. Journal of Agricultural and Resource Economics 39 (1), 34-46.

Marshall, G., 2008. Nesting, subsidiarity, and community-based environmental governance beyond the local scale. Int. J. Commons 2 (1), 75-97.

Meinzen-Dick, R., Chaturvedi, R., Domènech, L., Ghate, R., Janssen, M., Rollins, N., Sandeep, K., 2016. Games for groundwater governance: field experiments in Andhra Pradesh, India. Ecol. Soc. 21 (3), 38.

Meinzen-Dick, R., Janssen, M.A., Kandikuppa, S., Chaturvedi, R., Rao, K., Theis, S., 2018. Playing games to save water: collective action games for groundwater management in Andhra Pradesh, India. World Dev. 107, 40-53.

Mittone, L., Ploner, M., 2011. Peer pressure, social spillovers, and reciprocity: an experimental analysis. Exp. Econ. 14, 203-222.

Olson, M., 2009. The Logic of Collective Action: Public Goods and the Theory of Groups. Harvard University Press.

Ostrom, E., 1990. Governing the Commons: The Evolution of Institutions for Collective Action. Cambridge university press, New York, USA pp. 270.

Ostrom, E., 2009. Understanding Institutional Diversity. Princeton University Press, pp.
$1-355$.

Ostrom, E., Walker, J., Gardner, R., 1992. Covenants with and without a sword: selfgovernance is possible. Am. Polit. Sci. Rev. 404-417.

Pahl-Wostl, C., Craps, M., Dewulf, A., Mostert, E., Tabara, D., Tailleu, T., 2007. Social learning and water resources management. Ecol. Soc. 12 (2), 5.

Pahl-Wostl, C., Mostert, E., Tàbara, D., 2008. The growing importance of social learning in water resources management and sustainability science. Ecol. Soc. 13 (1), 24.

Palanisami, K., Meinzen-Dick, R., 2001. Tank performance and multiple uses in Tamil Nadu, South India. Irrig. Drain. Syst. 15 (2), 173-195.

Panagopoulos, C., 2010. Affect, social pressure and prosocial motivation: field experimental evidence of the mobilizing effects of pride, shame and publicizing voting behavior. Polit. Behav. 32, 369-386.

Rajabu, K.R., 2007. Use and impacts of the river basin game in implementing integrated water resources management in Mkoji sub-catchment in Tanzania. Agric. Water Manag. 94 (1-3), 63-72.

Raju, K.V., Shah, T., 2000. Revitalisation of irrigation tanks in Rajasthan. Econ. Polit. 52, 1930-1936.

Rege, M., Telle, K., 2004. The impact of social approval and framing on cooperation in public good situations. J. Public Econ. 88, 1625-1644.

Reyes-Garcia, V., Aubriot, O., Ariza-Montobbio, P., Galan-Del-Castillo, E., Serrano-Tovar, T., Martinez-Alier, J., 2011. Local perception of the multifunctionality of water tanks in two villages of Tamil Nadu, South India. Soc. Nat. Resour. 24 (5), 485-499.

Rockström, J., Karlberg, L., Wani, S.P., Barron, J., Hatibu, N., Oweis, T., Bruggeman, A., Farahani, J., Qiang, Z., 2010. Managing water in rainfed agriculture - the need for a paradigm shift. Agric. Water Manag. 97 (4), 543-550.

Singh, R., Garg, K.K., Wani, S.P., Tewari, R.K., Dhyani, S.K., 2014. Impact of water management interventions on hydrology and ecosystem services in GarhkundarDabar watershed of Bundelkhand region, Central India. J. Hydrol. 509, 132-149.

Singleton, S., Taylor, M., 1992. Common property, collective action and community. J. Theor. Polit. 4, 309-324.

Smith, A., 1759. The Theory of Moral Sentiments. Printed for A. Millar, London.

Soetevent, A.R., 2005. Anonymity in giving in a natural context - a field experiment in thirty churches. J. Public Econ. 89 (11-12), 2301-2323.

Speelman, E.N., van Noordwijk, M., Garcia, C., 2017. Gaming to better manage complex natural resource landscapes. Co-investment in ecosystem services: global lessons from payment and incentive schemes. In: Namirembe, S., Leimona, B., van Noordwijk, M., Minang, P.A. (Eds.), Co-Investment in Ecosystem Services: Global Lessons from Payment and Incentive Schemes. World Agroforestry Centre (ICRAF), Nairobi.

Woodhill, J., 2010. Capacities for institutional innovation: a complexity perspective. IDS Bull. 41 (3), 47-59. 